\title{
An examination of the generalization hypothesis of autoshaped keypecking
}

\author{
FERNANDO OBERDIECK, CARL D. CHENEY, and RICHARD A. STRONG \\ Utah State University, Logan, Utah 84322
}

\begin{abstract}
Two studies examined the hypothesis that initial autoshaped keypecks are generalized pecks from the lighted grain hopper to the lighted key. Pigeons in both studies autoshaped and maintained lighted keypecking even though magazine training and autoshaping was conducted without a magazine light. The results question the validity of the generalization account of autoshaped keypecking applied to all strains of pigeons.
\end{abstract}

Numerous experiments have identified the contingent relationship between keylight (CS) and food (UCS) as the crucial variable in the emergence of autoshaped keypecking (see Hearst \& Jenkins, 1974; Schwartz \& Gamzu, 1977, for reviews). However, Logan (1971) and Steinhauer, Davol, and Lee (1976) have suggested that initial keypecks in the autoshaping procedure are generalized from pecking the lighted food hopper. This account assumes that during magazine training, prior to autoshaping, the magazine light acquires discriminative control over pecking. That is, pecks in the lighted (indicating food availability) hopper are reinforced, whereas pecks in the unlighted (indicating no food) hopper are not reinforced. During subsequent autoshaping, generalized pecks to the illuminated key (CS) are therefore expected. These initial keypecks would then be reinforced immediately if a response-reinforcer contingency were in effect, or with a short delay if this contingency were absent. Sustained pecking, however, could be the result of generalization, the responsereinforcer contingency, or both.

Some data is difficult to account for within this generalization view of initial responses, however: for example, the finding that pigeons peck a key that signals the delivery of water injected directly into the mandible (Woodruff \& Williams, 1976) and the conditioning, in rats, of approach and contact responses to signals of brain stimulation (Peterson, Ackil, Frommer, \& Hearst, 1972). On the other hand, there is support for the generalization account. Both Hitzing and Safar (1970) and Steinhauer et al. (1976) demonstrated that magazinetrained pigeons will emit some pecks to a keylight condition that is never paired with food. Several investigators have also reported that, if pigeons are autoshaped with concurrently available keylights, the first peck is always to the same hue as the magazine light (Davol, Steinhauer, \& Lee, 1977; Fisher \& Catania, 1977; Sperling, Perkins, \& Duncan, 1977). Furthermore, since virtually all autoshaping studies have employed a magazine light, those studies in which autoshaped keypecking emerged may be construed as indirect evidence for the generalization account.

Perhaps the strongest support for this view is the Davol et al. (1977) failure to obtain autoshaped key- pecking with an unlighted food hopper. Although the generalization hypothesis would predict such a result, the Pavlovian account would not, since the contingent relationship between the keylight and food was maintained. The results of Davol et al. (1977) may, however, have been due to either the procedures employed or their failure to expose subjects to more than 200 keylightfood pairings. Perhaps the magazine light simply facilitates, but is not necessary for, the emergence of autoshaped keypecking. The following studies explored these alternatives.

\section{EXPERIMENT 1}

This experiment replicated that of Davol et al. (1977, Experiment 2) in which pigeons were both magazine trained and subsequently exposed to keylightfood pairings without a lighted food magazine.

\section{Method}

Subjects. Three experimentally naive wild homing pigeons served. Subjects were maintained at $75 \%$ of their ad-lib weight and individually housed with water available in their home cage at all times.

Apparatus. Subjects were trained in a three-key operant chamber with a white $7.5-\mathrm{W} 110-\mathrm{V}$ ac houselight located in the center of the ceiling. During keylight presentations, a white 28-V dc bulb transilluminated the center key. Side keys were accessible, but dark and nonfunctional. A complete description of the chamber is available in Oberdieck, Mueller, and Cheney (1977). Extraneous sounds were masked by white noise delivered into the experimental room and the chamber in which the experimental space was located. Electromechanical components in an adjoining room programmed experimental events and recorded data.

Procedure. On Day 1, subjects were individually placed in the experimental chamber with the houselight on, keys darkened, and the nonlighted food hopper elevated and filled with Purina Racing Checkers. After the subject had eaten for approximately $10 \mathrm{sec}$, the tray was lowered. On the following nine trials, the food tray was elevated at $30-\mathrm{sec}$ intervals, remaining in the raised position until the subject had eaten for approximately 3 sec. Immediately following these 10 trials, and again on Day 2, 100 keylight-food pairings were administered. Since all subjects rapidly gained weight, they were not exposed to autoshaping on Day 3. Starting on Day 4, subjects were exposed to only 40 keylight-food pairings per session. This was done in order to maintain the subjects near their experimental weights. In all autoshaping sessions, a white 8-sec keylight was immediately followed by a 3 -sec response-independent hopper presen- 
tation. Successive keylight presentations were separated by variable-time intertrial intervals (ITI) averaging $60 \mathrm{sec}$. The hopper light was never illuminated during either the magazine training or autoshaping procedures.

\section{Results and Discussion}

During magazine training, all subjects ate readily from the elevated but darkened hopper. Nonsystematic observations also revealed that the subjects continued to feed readily during autoshaping. However, in the first two sessions (which contained 100 keylight-food pairings each) subjects often failed to eat in the terminal portion of the session as they became sated.

Acquisition of keypecking was defined as occurring on the first trial of a consecutive sequence of five trials containing at least one response (Newlin \& LoLordo, 1976). Subjects 7, 8, and 9 met this criterion on Trials 186, 113, and $217($ mean $=172)$ and emitted their first CS peck on Trials 152,45 , and $52($ mean $=83)$, in that order. Figure 1 depicts the percentage of trials containing at least one response for these subjects. All subjects emitted some ITI pecks but these were mostly runover pecks. For two birds, first pecks were at the CS (lit key), whereas for Bird 7, the first peck may have been during the ITI or during hopper operation (runover). Subjects 7 and 9 responded on a majority of trials and maintained a high level of performance throughout. On the other hand, Subject 8 initially attained a relatively high level of performance, but began declining rapidly after Session 4 . The cause is unknown.

The data indicate quite clearly that some pigeons will autoshape without a lighted food magazine, contrasting sharply with the results reported by Davol et al. (1977). Of the five pigeons they exposed to similar conditions, only one responded and on only 2 out of 200 trials. Initially, we believed their failure to autoshape pigeons without a light hopper was a procedural artifact; however, the present results make this position untenable. Furthermore, it appears, since all our subjects emitted their first peck within 200 trials, that Davol et al. (1977) did expose their subjects to a sufficient number of trials.

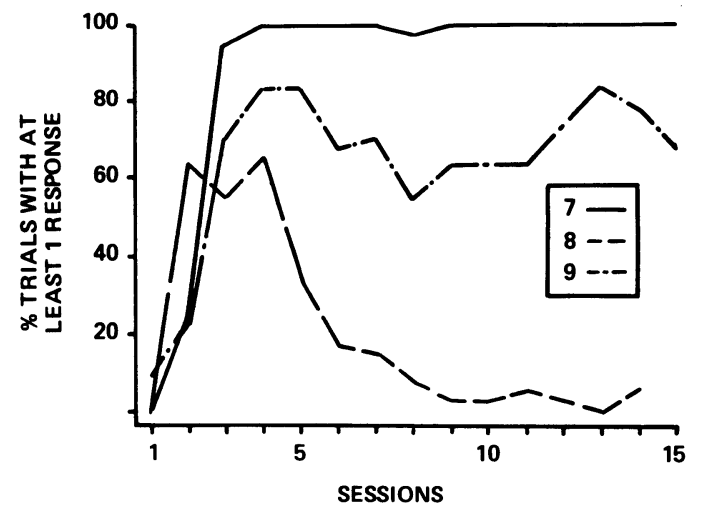

Figure 1. Percentage of trials with at least one response as a function of successive training sessions.

\section{EXPERIMENT 2}

A procedural complication we encountered in Experiment 1 was the rapid weight gain following magazine training and the first two autoshaping sessions. As a result, the subjects did not experience an uninterrupted sequence of daily autoshaping sessions. To overcome this problem, subjects in the present experiment were magazine trained on Day 1 and exposed to autoshaping (40 keylight-food pairings) on Day 2.

\section{Method}

Subjects. Three experimentally naive and three experimentally experienced wild homing pigeons were maintained as in Experiment 1.

Apparatus. The apparatus was the same as that in Experiment 1 .

Procedure. On Day 1, subjects were individually placed in the chamber with the houselight on, keys darkened, and the unilluminated food hopper raised and filled with chow. Subjects were given 20 magazine training trials, described in detail by Oberdieck et al. (1977). On Day 2 and subsequent days, subjects were exposed to autoshaping, which consisted of 40 keylightfood pairings daily; all temporal parameters were the same as in Experiment 1.

\section{Results and Discussion}

As in Experiment 1, all pigeons reliably ate from the darkened food hopper during magazine training and subsequent autoshaping. This procedure prevented the weight gains noted in Experiment 1 and allowed for uninterrupted daily sessions.

The experienced Subjects, S1, S2, and S3, met acquisition criterion on Trials 124,4 , and 127 (mean $=85$ ) and emitted their first CS pecks on Trials 7, 1, and 9 (mean $=5.6$ ), respectively. Subjects 4,5 , and 6 (naive group) met criterion on Trials 90,124 , and 82 (mean = 98.6) and emitted their first CS pecks on Trials 69, 92 , and 46 (mean $=69$ ), in that order. As in Experiment 1 , all subjects emitted some runover pecks. A Mann-Whitney $U$ test revealed no between-group difference with respect to trials to acquisition, although the experienced subjects did emit their first peck significantly sooner $(U=0, p=.05)$. Visual comparison of the percentage of trials with at least one response (Figure 2) reveals that the naive subjects reached a higher asymptotic level and in fewer sessions. Apparently, the auto-maintenance histories of the experienced subjects resulted in their erratic performance. The decline in performance of S3 is inexplicable. As in Experiment 1, two subjects in each group pecked first at the lighted key (CS) and the other two (S3, S6) pecked first during either the ITI or magazine operation.

A comparison of the naive subjects of Experiments 1 and 2 revealed no statistical difference with respect to trials to first peck or trials to acquisition. However, a visual comparison of Figures 1 and 2 suggests that the procedures employed in Experiment 2 resulted in more consistency, as measured by percentage of trials with at least one response. 


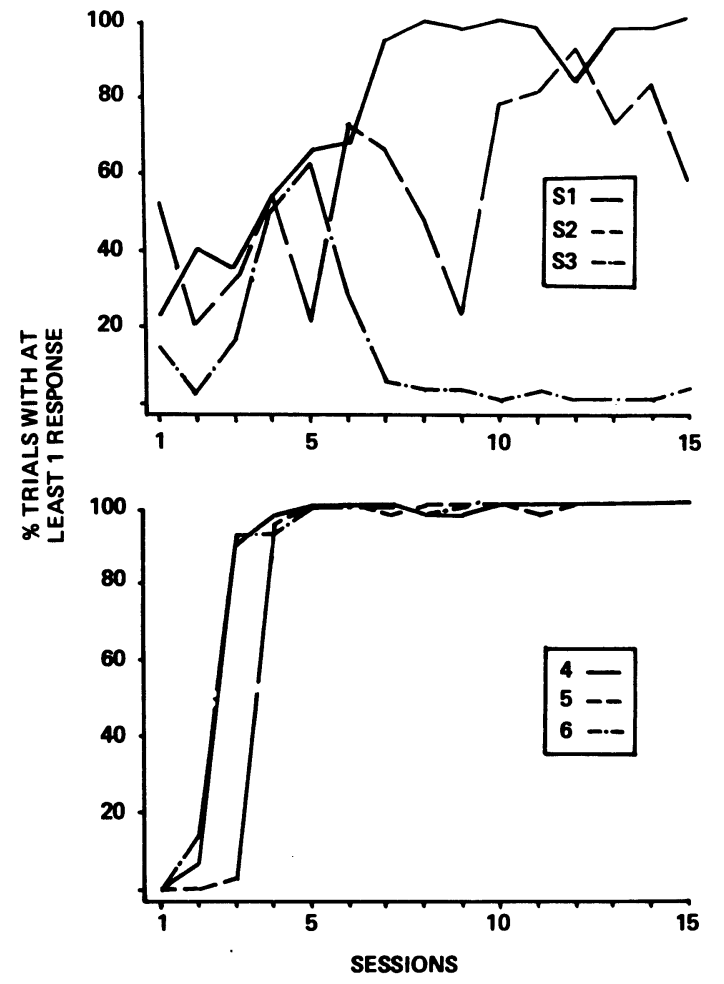

Figure 2. Percentage of trials with at least one response as a function of successive training days for the experienced (top) and naive (bottom) subjects of Experiment 2.

\section{GENERAL DISCUSSION}

The present data seriously weaken the generalization hypothesis advanced by Davol et al. (1977), Logan (1971), and Steinhauer et al. (1976). This hypothesis suggests that initial autoshaped keypecks are generalized pecks at the lighted food hopper. On the basis of this hypothesis (and some of their data), it would be predicted that magazine training and autoshaping without a magazine light would not engender autoshaped keypecking even though a signaling relation between the keylight and food was maintained. The results of the present experiments indicate that a magazine light is not necessary for the rapid $(<200$ trials) emergence of sustained autoshaped keypecking. What is crucial, apparently, is the temporal relationship of the CS (in this case, keylight) and food. The magazine light does, however, appear to facilitate the emergence of autoshaped keypecking, a point noted by Davol et al. (1977). Although the generalization account concerns only initial pecks, it also suggests that maintained responding might reflect some generalization. The maintained responding at the lighted key CS in the present studies indicates that generalization is not a crucial factor in automaintenance. Six of the 9 birds also pecked first at the CS rather than at the nonlighted key, which further contrasts with the generalization account.

We are not sure what to make of the difference between the present findings and those reported by Davol et al. (1977). Although in Experiment 1 we employed procedures very similar in all respects to those of Davol et al. (1977), they used adult Columba pigeons, whereas we used wild homing pigeons. Perhaps autoshaping without a magazine light reveals strain differences that are not detectable within the more conventional autoshaping procedure, that is, with a magazine light. The literature contains many examples of behavioral difference due to strain or domestication in rats (e.g., Mitchell, 1976; Shurman \& Katzev, 1975) and chickens (e.g., Gallup, Ledbetter, \& Maser, 1976). Furthermore, Powell (1975) has reported that crows fail to autoshape, thereby questioning the generality of autoshaping even within avians. However, to our knowledge, no one has suggested the possibility of differences in pigeons as a function of strain or domestication with regard to autoshaping. Unfortunately, the present data leaves this question unanswered, although it does seriously question the universality of the generalization account of initial autoshaped keypecks.

\section{REFERENCES}

Davol, G. H.. Steinhauer, G. D., \& Lee, A. The role of preliminary magazine training in acquisition of the autoshaped keypeck. Journal of the Experimental Analysis of Behavior, 1977, 28, 99-106.

Fisher, M. A.. \& Catania, A. C. Autoshaping: Relation of feeder color to choice of key color. Bulletin of the Psychonomic Society, 1977, 9. 439-442.

Gallup, G. G., JR., Ledbetter. D. H., \& Maser. J. D. Strain differences among chickens in tonic immobility: Evidence for an emotionality component. Joumal of Comparative and Physiological Psychology. 1976, 90. 1075-1081.

Hearst, E., \& Jenkins. H. M. Sign tracking: The stimulus reinforcer relation and directed action. Austin. Tex: The Psychonomic Society, 1974.

Hitzing, E. W.. \& Safar, T. Autoshaping: The conditions necessary for its development and maintenance. Psychological Record, 1970, 20. 347-351.

LogAN. F. A. Incentive theory, reinforcement, and education. In R. Glaser (Ed.), The nature of reinforcement. New York: Academic Press, 1971.

Mitchell, D. Experiments on neophobia in wild and laboratory rats: A reevaluation. Journal of Comparative and Physiological Psychology, 1976, 90, 190-197.

Newlin, R. J., \& LoLordo, V. A comparison of pecking generated by serial, delay, and trace autoshaping procedures. Journal of the Experimental Analysis of Behavior. 1976, 25, 227-241.

Oberdieck, F., Mueller, D. L., \& Cheney, C. D. Autoshaping the pigeon's keypeck in a dark chamber. Bulletin of the Psychonomic Society, 1977, 9, 317-318.

Peterson, G. B., Ackil, J., Frommer, G. P., \& Hearst, E. Conditioned approach and contact behavior toward signals for food or brain stimulation reinforcement. Science, 1972. 177, 1009-1011.

Powell, R. W. Response-independent reinforcement in the crow: Failure to obtain autoshaping or positive automaintenance. Bulletin of the Psychonomic Society, 1975, 6, 513-516.

Schwartz, B., \& GAmzu, E. Pavlovian control of operant behavior. In W. K. Honig \& J. E. R. Staddon (Eds.), Handbook of operant behavior. Englewood Cliffs, N.J: Prentice-Hall, 1977.

Shurman, A. J., \& Katzev, R. D. Escape/avoidance responding in rats depends on strain and number of inescapable preshocks. Journal of Comparative and Physiological Psychology, 1975, 88, 548-553.

Sperling, S. E., Perkins, M. E., \& Duncan, H. J. Stimulus generalization from feeder to response key in the acquisition of autoshaped pecking. Journal of the Experimental Analysis of Behavior, 1977, 27, 469-478.

Steinhauer, G. D., Davol, G. H., \& Lee, A. Acquisition of the autoshaped key peck as a function of amount of preliminary magazine training. Journal of the Experimental Analysis of Behavior, 1976, 25, 355-359.

WoodrufF, G., \& Williams, D. R. The associative relation underlying autoshaping in the pigeon. Journal of the Experimental A nalysis of Behavior, 1976, 26, 1-13. 